\title{
The Impact of Acculturation on the Leadership Style of Afghan American Registered Nurses Working in the United States' Healthcare System
}

\author{
Belal A. Kaifi ${ }^{1}$ - Bahaudin G. Mujtaba ${ }^{2}$ - Mustafa G. Mujtaba ${ }^{3}$
}

Accepted: 18 March 2021 / Published online: 26 May 2021

(C) The Author(s), under exclusive licence to Springer Science+Business Media, LLC, part of Springer Nature 2021

\begin{abstract}
The impact of acculturation on leadership style is an important topic for the global community, especially during stressful years of the Covid-19 pandemic. A quantitative, non-experimental, descriptive-correlational design using primary retrospective data was employed in this study. We used established instruments such as the Acculturation Rating Scale Questionnaire and the Leadership Style Questionnaire (LSQ) with 172 working adult respondents in the U.S. Health System as registered nurses. The results showed that Afghan male and female nurses tended to identify with the Afghan culture or the American culture, not both. Afghan male nurses' relationship-oriented leadership was related to both Afghan and (more weakly) American acculturation (the more acculturation, the more relationship orientation).
\end{abstract}

Keywords Afghan-American · Registered nurse · Acculturation · Leadership style · Culture

\section{Introduction}

The United States is known as a melting pot or as the land of opportunity for current citizens and prospective contributors through entrepreneurship and service to society. When entering the U.S., each individual brings unique traditions, cultures,

Belal A. Kaifi

belalkaifi@yahoo.com

Bahaudin G. Mujtaba

mujtaba@nova.edu

Mustafa G. Mujtaba

mmujtaba@fgcu.edu

1 Business Administration, Trident University, 5757 Plaza Dr. \#100, Cypress, CA 90630, USA

2 Nova Southeastern University, 3301 College Avenue, Fort Lauderdale, FL 33314-7796, USA

3 Department of Biological Sciences, Florida Gulf Coast University, Whitaker Hall, Room 117, 10501 FGCU Boulevard South, Fort Myers, FL 33965, USA 
and customs to this land of opportunity. Non-native health field workers are making the workforces more culturally diverse, although in the United States, about 60 percent of new entrances into the job market are expected to be from the dominant culture: white, native-born Americans (Tjosvold \& Leung, 2016). The focus of this current study is Afghan American nurses practicing in the U.S. health system.

Acculturation is one of the frequently used variables in career development research because of its significance to many aspects of career development for immigrants. According to Miller and Kerlow-Myers (2009), acculturation has been linked to a number of important career outcomes such as job choice and satisfaction, performance reviews, career decision self-efficacy, and occupational stress. Of course, this year of pandemic is different as "The novel coronavirus and the disease it causes, COVID-19 is one of the most unpredictable global public health crises in recent times" (Fernandez \& Shaw, 2020, p. 1). Sadly, our lives have been turned upside down and everyone has received acculturation regarding safety, such as social distancing, working from home, and wearing of mask (Korman \& Mujtaba, 2020).

The acculturation issue addressed in this research is focused on the dilemma facing immigrants and refugees settling in the United States, which is how much of the culture should or can immigrants maintain and still be able to function in their professional fields among the dominant culture. Historically immigrants will settle in communities where others from the same country reside (Hirschman, 2013). Many researchers (Mujtaba, 2019; Nguyen et al., 2014a, b) have attempted to examine the dominant leadership orientation of individuals from different contexts because of the implications for cross-cultural management, individuals who are expatriates, the repatriation process, and to help provide awareness and understanding of different cultural norms among individuals living and working in a global community (Tajaddini \& Mujtaba, 2010; Mujtaba \& Balboa, 2010; Mujtaba, 2010).

The general problem is that non-native healthcare workers are often caught between two worlds (Aseel, 2003): deciding to assimilate into the dominant culture of the United States or to maintain their culture, which often results in personal familial and workplace struggles (Ludwick \& Silva, 2000; George, 1993). As such, there are two research questions:

RQ 1. Are there any correlations between acculturation, gender, education level, income, primary language, and task-oriented/relationship-oriented leadership style?

RQ 2. Can acculturation, gender, education level, income, and primary language predict task-oriented/relationship-oriented leadership?

\section{Literature Review}

A literature search was conducted using various database sources to retrieve peerreviewed and scholarly information on leadership styles. Starting in the 1950s, a series of studies on leadership styles and behaviors were conducted at Ohio State University and the University of Michigan (Colquitt et al., 2011). The researchers at Ohio State University studied leadership and, as a result, two main leadership 
style dimensions were discovered: initiating structure and consideration (Fleishman, 1953). Around the same time, similar studies were conducted by the University of Michigan that identified two leadership style dimensions: production-centered (taskoriented) and employee-centered (relations-oriented) (Katz et al., 1950). Judge et al. (2004) concluded that consideration and initiating structure behaviors were linked to follower motivation and leader effectiveness, with consideration (relationship) being somewhat more important.

Cann and Siegfried (1990) examined the relationship between initiating structure and consideration leadership styles on the one hand and feminine and masculine behaviors on the other. The results showed that consideration is perceived as more feminine and initiating structure is perceived as more masculine. Politis et al. (2018) investigated the relationship between initiating structure and consideration leadership styles, but also creativity and innovation in organizations operating in Arabic and European cultures. The findings of the study revealed that managers with consideration leadership style influenced more positively and significantly the factors of creativity and innovation compared to the managers that exercise initiating structure leadership.

Cowsill and Grint (2008) conducted a study that focused on leadership, task, and relationship. The authors discussed the long debate between leadership style and, more specifically, being task or relationship oriented. The study was aimed to evaluate the leadership of the Royal Air Force and the results showed support for both the task and relationship leadership orientations. Cowsill and Grint (2008) asserted that leaders were both focused on the achievement of missions and goals, their relationships with subordinates, and at times the focus was both task oriented and relationship oriented.

\section{Nursing and Leadership}

Nurses play a critical role in patient care, are important to the governance of the healthcare organizations, and are involved in almost every field of medicine (Curran and Sigma Theta Tau International, 2016; Hunt, 2017). The nursing profession has evolved into various specialties that include nurse practitioners, nurse anesthetist, home care nurses, critical care nurses, oncology nurses, intensive care nurses, pediatric nurses, geriatric nurses, and nurse educators, among others (Fitzpatrick et al., 2017). Furthermore, nurses are the first healthcare providers, and sometimes the only ones, many patients see during inpatient and outpatient visits. In addition, nurses interact with their patients at a higher frequency and longer duration as compared to their medical doctor counterparts, and in some areas of health service delivery have replaced doctors, especially in primary care visits, to increase efficiency, services and cost savings (Lockwood, 2020). Thus, nurses provide an essential service to patient care and are increasingly involved in various fields of medicine.

Over the years, nursing has evolved from a modest caretaker role to a dynamic and challenging profession which requires adaptation to constant change and coordination of personnel, policies, and procedures. Cultural and social awareness is crucial to effective nursing practice and academic institutions have adjusted accordingly 
this year due to the Covid-19 pandemic (Fernandez \& Shaw, 2020). The choices that nurses make in their careers communicate what they value (Blais, 2019). As such, identifying and developing nursing leaders is one of the greatest challenges faced by the nursing profession (Fernandez \& Shaw, 2020; Scully, 2015). The concept of leadership is a complex and multi-dimensional phenomenon because there are many definitions and theories of leadership but no universally accepted definitions or theories. However, there is increasing clarity surrounding what true nursing leadership is, and how it differs from management (Grossman \& Valiga, 2012).

Nursing leadership includes supporting clinical colleagues and inspiring followers to transform themselves and their situations through development of talents and formation of reciprocal relationships (Caplin-Davies, 2003). One of the most important points to note is that leadership is not necessarily tied to a position of authority (Grossman \& Valiga, 2012; Rigoloski, 2013). Due to a lack of authority, the high-usage of teams in healthcare settings, and constant changes in the healthcare industry, nurses can be considered informal leaders who rely upon authentic leading rather than power-wielding tactics available to formal leaders such as managers (Pielstick, 2000).

To navigate the complexities of the modern healthcare environment, bedside nurses must have informal clinical leadership skills to support and empower each other as they make important decisions at the point of care (Rogers, 2017). Transitioning into a professional role as a nurse is challenging. In addition, being able to learn new techniques and perform assigned tasks while getting to know and developing relationships with colleagues can be stressful (Frögéli et al., 2019).

\section{Leadership and Acculturation}

There have been many studies conducted on leadership and acculturation across the globe (Zareen et al., 2015). Zoppi (2004) examined the relationship of self-perceived leadership, acculturation, and individualistic versus collectivistic behaviors in female Latino leaders using the Acculturation Rating Scale for Mexican AmericansII (ARSMA-II). The study used a quantitative, descriptive, and exploratory research approach to answer the research questions. One finding was that transformational leadership behaviors were significantly related to collectivism factors, whereas transactional leadership behaviors were significantly related to individualistic factors. The author mentioned that additional research should target sex differences in leadership and acculturation, including individualism versus collectivism styles.

A mixed-methods study by Iron Cloud (2019) on the Oglala Lakota people of the Pine Ridge Indian Reservation found that the participants found themselves in a time of rapid change, a time of biculturalism and multiculturalism. One of the primary questions of this study focused on whether acculturation predicts leadership styles. The levels of acculturation were low, traditional (17.6\%), moderate, bicultural $(68.6 \%)$ and high, assimilated (13.7\%). Qualitative themes revealed leadership values similar to servant leadership among all six respondents regardless of acculturation level. 
Trevino (2010) conducted a study on acculturation and leadership styles of elected Latino leaders. The purpose of this exploratory study was to examine how a group of elected Latino leaders scored on an acculturation and leadership scale. The study also provided an understanding of how elected Latino leaders define and experience leadership based on their acculturation level and leadership styles. Trevino (2010) defined acculturation levels as individuals progressing through the process of socialization changes in thinking about their values and traditions. The stages each individual goes through represent levels of adaptation to the dominant society often involving religious practices, diet, healthcare and social institutions. The results of the study also add to the current body of literature on Latino leadership because the findings confirmed an association between acculturation level and leadership style. The author pointed out that the absence of sex in the study was attributed to the lack of a single probing question on sex within the current research surveys utilized.

Paris (2003) conducted a study on acculturation, assimilation, leadership styles and its consequences on job satisfaction. The study examined the consequences of culture for job satisfaction of six cultural groups in the Honolulu Fire Department (HFD). Results of the study indicated that the six cultural groups (American, Chinese, Filipino, Japanese, Part-Hawaiian, and "others") of the Honolulu Fire Department showed evidence of assimilation. Upon comparison of cultural group scores with corresponding Motherland scores, most HFD cultural groups were shown to have retained very little remnants of culture from their Motherland. The overall results indicated that most groups were satisfied with job location and physical working conditions, but were less satisfied with personal growth and the least satisfied with leadership styles and earnings.

\section{Afghan Leadership Style}

For the past century, the topic of leadership style and leader-follower relationships has been investigated by a number of scholars (Pielstick, 2000; Rogers, 2017; Mujtaba \& Sadat, 2010). Many scholars have questioned what the most effective method is for leading others. Generally, a person's leadership style tends to be a consistent behavior that is exercised in a number of predicaments. As explained by Mujtaba (2019), the two main types of leadership styles that are relevant to this research are the taskoriented and relationship-oriented.

The work of Mujtaba and Sadat (2010) focused on the task and leadership orientation of Afghans living in Afghanistan (i.e., locals) and Afghan expatriates. The total number of local Afghan participants was 106 (Males, $n=84$; Females, $n=22$ ) and the total number of expatriates was 219 (Males, $n=123$; Females, $n=96$ ). The expatriate respondents were mostly working adults living in the United States but with years of work experience and socialization in Afghanistan. The study used two versions of a questionnaire. One version was in English and the other version was translated into Dari, the dominant language of Afghanistan. The Dari version was distributed to individuals working in Herat, Afghanistan. Overall, the results showed that local males and females had similar "high" scores on both task and relationship orientations. However, expatriate males and females who were mostly 
adults living in the U.S. scored differently on the questionnaire. Expatriate males had "high" scores for both task and relationship orientations, whereas expatriate females had moderately high scores for task orientation and high scores for relationship orientation.

Azizi (2008) conducted a study on leaders of higher education in Afghanistan that consisted of interviewing seven male leaders in higher education and seven female leaders in parliament. The author explained the importance of Afghan leaders using leadership styles that will instigate the overall scheme of a powerful nation building strategy. As a result of his research, Azizi (2008) developed the Cultural Exchange Model of Leadership for Afghanistan which encompasses Eastern viewpoints on literature, Islamic viewpoints on leadership, Western styles of leadership, and cultural considerations regarding leadership.

Mujtaba and Kaifi (2010) conducted a study on the transformational leadership style of Afghans $(n=300)$ and Americans $(n=502)$. The researchers concluded that female American respondents had a significantly higher transformational leadership orientation than their Afghan female colleagues. Younger Afghans had a significantly higher tendency toward a transformational leadership orientation than their American counterparts. Moreover, Mujtaba and Kaifi (2010) also conducted a study on the leadership orientation of working adults in Afghanistan $(n=219)$ compared to the U.S. $(n=87)$. The small number of American females $(n=31)$ and the survey not being translated to the native language of Afghanistan were both major limitations of the study. However, one main result showed that Afghan females had significantly lower task scores when compared to their relationship scores.

A study by Rahmani (2016) investigated political leadership in Afghanistan. The author pointed out that political leadership and the actual characteristics of an Afghan leader have never been studied. According to the Rahmani (2016) study, some of the most important attributes of a good leader are being educated, having morals and values, and being a devout Muslim. The researcher also explained how different ethnic groups within Afghanistan had a different definition for what a leader is. For example, Pashtuns associate the word elder to leadership while Tajiks associate the word guide to leadership.

\section{American Leadership Style}

In the U.S., effective leaders are expected to be able to focus on tasks while maintaining and developing relationships at the same time. Both leadership orientations are important, and, in some cases, it may be more beneficial to focus more on tasks than relationships or vice versa. In other cases, depending on the industry, leaders could be high in one orientation like task or the other such as relationship (Mujtaba, 2019; Nguyen et al., 2014c; Mujtaba et al., 2010; Schermerhorn et al., 2008; Blake \& Mouton, 1966). According to Sherwood and DePaolo (2005), the task context includes how a manager will complete tasks with and through people which has to do with planning, organizing, leading, and controlling management functions. The authors further explained that the relationship context involves showing concern for subordinates, providing unconditional emotional support, and open communication. 
Mujtaba and Alsua (2011) examined the management orientation of working adults and business students in the United States by comparing the leadership perception of 484 respondents from Alaska and Florida regions. The researchers reported that Americans had high scores on both task and relationship orientations but scored a little higher on the relationship-orientation, possibly because of the high emphasis on teamwork and collaboration in universities and the work environment.

Several researchers have discussed the task versus relationship dichotomy and recommended leaders to be both task and relationship oriented. For example, Begum and Mujtaba (2016) emphasized that leaders should be flexible and accommodate the contextual demands in their leadership style to maintain a healthy balance of task and relationship orientation. Similarly, Mujtaba et al. (2010) explained the importance of having a balance in order for organizational goals to be accomplished in a timely manner. In addition, according to Cowsill and Grint (2008), leaders that overfocus on building relationships without a purpose or over-focus on task completion are unlikely to succeed in the end. Kavanaugh (1986) noted that the combination of task and relationship orientations have the capacity to unify teams and influence leader effectiveness. Overall, in this study with Afghan-American healthcare professionals, the objective is to know the correlations between acculturation, gender, education level, income, primary language, and task-oriented/relationship-oriented leadership style, while trying to find out if acculturation, gender, education level, income, and primary language predict task-oriented/relationship-oriented leadership styles.

\section{Methodology}

In this study, the research questions asked if gender, education, income, primary language spoken at home, level of Afghan acculturation, and level of American acculturation predicted task- and relationship-oriented leadership styles, respectively. Participants were Afghani-American adults currently working in the US Health System as nurses with one or both parents originally from Afghanistan. Sampling combined purposeful convenience and targeted snowball samples recommended for hard-to-reach populations (Dusek et al., 2015) by inviting potential participants to participate through social media sites and professional networks specific to Afghans, primarily the Facebook group Afghan Health Initiative, comprised of 2,500 Afghan Americans affiliated with healthcare. The invitation included the link to the SurveyMonkey survey.

Data were collected with the 61-item Acculturation and Leadership Survey for Nurses, a researcher-created compilation of validated published surveys on acculturation and leadership with select demographic questions. Levels of acculturation were of two types, to the Afghan culture and to the American culture, and measured by statements from Cuéllar et al. (1995) Acculturation Rating Scale Questionnaire for Hispanics/Latinos (ARSMA-II), modified with permission by replacing Latino terms with Afghan terms (e.g., My thinking is done in the Dari/Pashto language) or American terms (e.g., My thinking is done in the English language). Participants were asked to rate how often they engaged in the stated behavior using a 5-point 
Likert frequency scale ( $1=$ not at all, $5=$ extremely often or almost always) on 12 survey items for each culture; numeric values were summed for a possible range of $12-60$ points.

Leadership orientation was also of two types, task-oriented leadership and relationship-oriented leadership, and collected with Northouse's (2004) Leadership Style Questionnaire (LSQ). Ten statements for each type of leadership asked participants to rate how often they engaged in the stated behavior (e.g., task-oriented: tells group members what they are supposed to do; relationship-oriented: help others feel comfortable in the group). Responses were on a 5-point Likert scale of frequency ( $1=$ never, $5=$ always). Numeric values are summed for a possible range of 10-50 points. Total scores can be interpreted categorically $(10-24=$ very low; $25-29=$ low; $30-34=$ moderately low; $35-39=$ moderately high; $40-44=$ high; $45-50=$ very high).

For demographics, gender was dummy coded with men as the reference category. Education was measured categorically with 6 levels ranging from high school/vocational to graduate school. Income was measured on a continuous scale as thousands of USD annually. Primary language spoken at home had two dummy coded levels, Dari/Pashto (reference category) or English.

Screening for normality, linearity, homoscedasticity, and outliers (Tabachnick \& Fidell, 2019) showed that one man, case 50, was an extreme low outlier on both acculturation measures and was removed from further analyses. Four participants did not provide income data (one man, case 134, and three women, cases 100, 137 and 142), final $\mathrm{N}=167$ participants. Research questions were addressed with four multiple regression tests, one each for task- and for relationship-oriented leadership for men and women separately. Adjusted $\mathrm{R}^{2}$ statistics are given in models with more than one predictor.

\section{Results}

The sample was approximately split by gender ( 84 men, $49 \%$; 87 women, $51 \%$ ). The majority of participants $(63 \%)$ held a 4 year college degree. Annual income was variable $(M=\$ 93,802, S D=\$ 31,110, \min =\$ 30,000, \max =\$ 300,000)$. The sample was also approximately split by the dominant language that participants used at home (49\% spoke Dari/Pasto, 51\% spoke English). Participants exhibited Afghan cultural behaviors moderately often on average (Afghan acculturation $M=38.93$, $S D=8.15$, Cronbach's $\alpha=0.94$, ) and American cultural behaviors very often (American acculturation $M=47.03, S D=7.33$, Cronbach's $\alpha=0.84)$. Task-oriented leadership behaviors were used sometimes on average $(M=35.40, S D=7.40$, Cronbach's $\alpha=0.90)$ whereas relationship-oriented leadership behaviors were used frequently $(M=39.27, S D=8.12$, Cronbach's $\alpha=0.95)$.

The modal man had a 4-year college degree, annual income of $M=\$ 95,987$ USD $(S D=\$ 36,976)$, moderately high Afghan acculturation score $M=38.09$ ( $S D=8.48$, $\min =19, \max =60)$, very high American acculturation score $M=46.04(S D=7.85$, $\min =25, \max =60$ ), and primarily spoke English at home ( $45 \%$ or 38 men spoke Dari/Pashto, 55\% or 46 men spoke English), $n=84$ men. The modal woman had a 
four-year college degree, an annual income of $M=\$ 92,283$ USD ( $S D=\$ 23,550)$, a moderately high Afghan acculturation score $M=39.85, S D=7.77$, a very high American acculturation score $M=48.00, S D=6.71$, and primarily spoke Dari/ Pashto at home (52\% or 45 women spoke Dari/Pashto, $48 \%$ or 42 women spoke English), $n=87$ women.

\section{Results of t-Test for Acculturation}

Because of the research interest in gender differences, acculturation and leadership scores were compared across men and women, and illustrated on Fig. 1. Afghan acculturation levels did not differ significantly between men and women $(t(169)=-1.41, p=0.160$, black bars in Fig. 1; small gender effect, Cohen's $d=0.21$; men: $M=38.09$, $S D=8.48$; women: $M=39.85, S D=7.77)$. American acculturation levels also did not differ between men and women $(t(169)=-1.76, p=0.080$, white bars Fig. 1; small gender effect Cohen's $d=0.27$; men: $M=46.03, S D=7.85$; women $M=48.00, S D=6.71$ ).

Both men and women reported significantly higher levels of American than Afghan acculturation (white vs black bars Fig. 1; men: $t(83)=-5.12, p<0.001$; medium effect of acculturation Cohen's $d=0.56$; strong negative correlation $r(82)=-0.51, p<0.001$; women: $t(86)=-6.26, p<0.001$; medium effect of acculturation Cohen's $d=0.67$, strong negative correlation $r(85)=-0.40, p<0.001)$.

\section{Results of t-Test for Leadership}

Levels of relationship-oriented leadership differed significantly between men and women $(t(169)=-9.96, p<0.001$, vertical striped bars $)$. Women reported significantly higher levels (women $M=43.03, S D=4.35)$ compared to men $(M=35.38$,

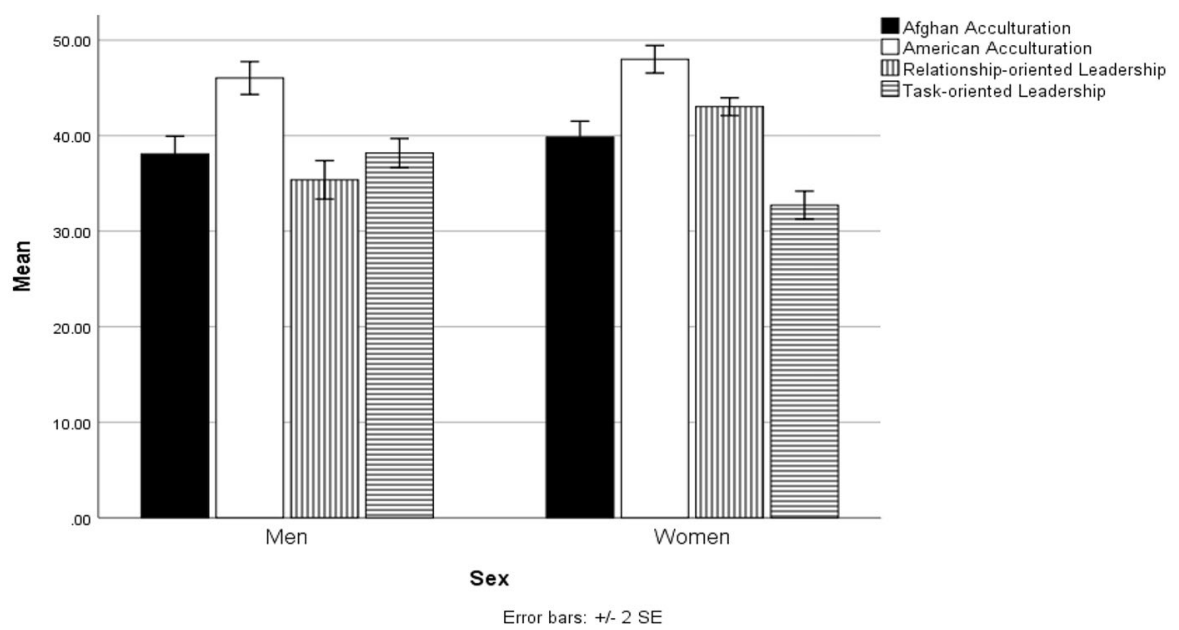

Fig. 1 Gender differences in acculturation and leadership styles 
$S D=9.24$ ) for a strong gender effect (Cohen's $d=1.12$ ). Levels of task-oriented leadership also differed between men and women $(t(169)=5.17, p<0.001$, horizontal striped bars). Men reported higher levels $(M=38.18, S D=6.96)$ compared to women $(M=32.72, S D=6.83)$ for a strong gender effect (Cohen's $d=0.79)$.

Men showed a statistical trend from slightly higher levels of task- versus relationship-oriented leadership $(t(83)=-1.94, p=0.060$, men's horizontal and vertical striped bars, Fig. 1), a small effect of styles (Cohen's $d=0.21$ ), and medium negative correlation between styles $(r(82)=-0.37, p=0.001)$. Women reported a significantly higher level of relationship- than task-oriented leadership styles, $(t(86)=12.92$, $p<0.001$ ), a very large effect of styles (Cohen's $d=1.38$ ), and negligible correlation between styles $(r(85)=0.17, p=0.110$, women's vertical to horizontal striped bars, Fig. 1).

\section{Acculturation and Leadership Orientation Correlation}

Table 1 shows a correlation matrix listing the associations between acculturation and leadership separately for men (above the diagonal) and women (below the diagonal). For the men, the largest correlation was the negative correlation between Afghan and American acculturation. Next largest in magnitude was the medium negative correlation between relationship- and task-oriented leadership and positive correlation between Afghan acculturation and relationship-oriented leadership. Smaller relationships arose in the positive correlation between American acculturation with relationship-oriented leadership but negative correlation with task-oriented leadership. Task-oriented leadership was unrelated to Afghan acculturation.

For the women, the largest correlation was the negative correlation between Afghan and American acculturation. The second largest correlation was the positive correlation between Afghan acculturation and task-oriented leadership. The correlation next in magnitude was the positive correlation between relationship-oriented leadership and Afghan acculturation. The correlation between relationship- and task-oriented leadership was small. Finally, the association of the smallest magnitude for the women arose from the negligible correlation between American acculturation and leadership styles.

Table 1 Correlation matrix of acculturation and leadership

\begin{tabular}{|c|c|c|c|c|}
\hline & \multicolumn{2}{|c|}{ Acculturation } & \multicolumn{2}{|c|}{ Leadership Orientation } \\
\hline & Afghan & American & Relationship & Task \\
\hline Afghan Acculturation & & $-0.514^{* *}$ & $0.354^{* *}$ & 0.048 \\
\hline American Acculturation & $-0.404^{* *}$ & & $0.231^{*}$ & $-0.218^{*}$ \\
\hline Relationship-oriented Leadership & $0.247^{*}$ & 0.024 & & $-0.368^{* *}$ \\
\hline Task-oriented Leadership & $0.331^{* *}$ & -0.061 & 0.172 & \\
\hline
\end{tabular}

*Correlation is significant at the 0.05 level (2-tailed). **Correlation is significant at the 0.01 level (2-tailed). Men's correlations are above the blank diagonal line ( $n=84 \mathrm{men})$. Women's correlations are below the blank diagonal line $(n=87$ women) 


\section{Multiple Regression Tests}

The research questions asked whether gender, education, income, primary language spoken at home, Afghan acculturation, and/or American acculturation predicted task-oriented leadership and relationship-oriented leadership, respectively. Because of sex differences in the modal demographic characteristics and leadership-acculturation relationships (Table 1), these questions were addressed for men and women with separate multiple regressions. The data were tested and found to meet the regression assumptions of adequate sample size, linear relationships between leadership styles and predictor variables, univariate normality, absence of outliers, normality and homoscedasticity of residuals, multivariate normality, absence of multicollinearity, adequate tolerance values, and absence of autocorrelation. Table 2 summarizes the amount of variance accounted for and the regression lines. Regression results follow.

Predictors of men's task-oriented leadership Relationship-oriented leadership (Table 1), American acculturation (Table 1), and primary language spoken at home $(r(81)=-0.179, p=0.050)$ correlated significantly with task-oriented leadership and were entered into the regression as predictors. Relationship-orientation emerged as the only significant predictor, so the model was re-specified. Relationship-orientation accounted for a significant $14 \%$ of the variance in task-orientation $\left(R^{2}=0.14\right.$, $F(1,82)=12.85, p=0.001)$. The regression line for predicting task-orientation was $47.98-0.28$ (relationship-orientation score).

Predictors of men's relationship-oriented leadership Relationship-orientation correlated with all of the potential predictor variables, so all were entered into the regression. All were significant predictors except education so the model was re-specified. Demographics, both types of acculturation, and task-oriented leadership accounted for a significant $50 \%$ of the variance in relationship-oriented leadership (adjusted $\left.R^{2}=0.52, F(5,77)=17.69, p<0.001\right)$. The regression line for predicting men's relationship-oriented leadership was 4.76 (primary language spoken at home) +0.75 (Afghan acculturation) +0.40 (American acculturation) - 0.37 (task-oriented leadership) -0.00007 (annual income)-6.59.

Table 2 Regression line formulas by gender and leadership orientation

\begin{tabular}{|c|c|c|}
\hline Leadership Orientation & $\mathrm{R}^{2}$ & Regression Line Formula \\
\hline Men's Task & $14 \%$ & $47.98-0.28$ (relationship-orientation score) \\
\hline Men's Relationship & $50 \%$ & $\begin{array}{l}4.76 \text { (primary language spoken at home })+0.75 \text { (Afghan accul- } \\
\text { turation) }+0.40 \text { (American acculturation) }-0.37 \text { (task-oriented } \\
\text { leadership) }-0.00007 \text { (annual income })-6.59\end{array}$ \\
\hline Women's Task & $17 \%$ & $10.73+2.32$ (highest education level) +0.32 (Afghan acculturation) \\
\hline Women's Relationship & $7 \%$ & $34.66+0.12$ (Afghan acculturation) and 0.00004 (annual income) \\
\hline
\end{tabular}


Predictors of women's task-oriented leadership Afghan acculturation (Table 1) and highest educational level $(r(82)=0.23, p=0.107)$ correlated significantly with task-oriented leadership and were entered as predictors. Together they accounted for a significant $17 \%$ of the variance in task-orientation (adjusted $R^{2}=0.17, F(2$, $84)=9.77, p<0.001)$. The regression line for predicting women's task-oriented leadership was $10.73+2.32$ (highest education level) +0.32 (Afghan acculturation).

Predictors of women's relationship-oriented leadership Afghan acculturation (Table 1) and annual income $(r(82)=0.23, p=0.017)$ correlated significantly with relationship-oriented leadership and were entered as predictors. The model was significant, accounting for $7 \%$ of the variance in relationship-oriented leadership (adjusted $\left.R^{2}=0.07, F(2,81)=4.33, p=0.016\right)$. The regression line for predicting women's relationship-oriented leadership was 34.66+0.12 (Afghan acculturation) and 0.00004 (annual income).

\section{Discussion}

This research with Afghan-American healthcare professionals was initiated to determine if there are any associations among cultural acculturation and demographic variables and leadership styles. We also wanted to know if acculturation, gender, education level, income, and primary language can actual predict one's leadership orientation toward tasks and relationships.

Our results concluded that male Afghan-American healthcare respondents tended to identify with either the Afghan culture or the American culture, but not necessarily both. These findings confirm previous literature that acculturation often influences one's identification with culture and career choices (Miller \& Kerlow-Myers, 2009). This is perhaps related to the respondent's years of socialization and tenure with the culture, or it may be associated with the age when the healthcare professional became cross-cultural. As such, due to the result of this research, there are a number of implications for analysis, discussion, future research, and policy making consideration by healthcare professionals and public sector officials (Senathip et al., 2017). For example, future researchers can attempt to study years of socialization into the culture as an independent variable. Another possible explanation might be the respondent's current familial connection with the Afghan culture. For example, is the respondent still living with Afghan parents, is he or she married to an Afghan spouse, do they watch Afghan television at home, and do they regularly travel to their ancestral home to visit relatives and collaborate with the locals?

Another finding was that male respondents tended to predominantly exhibit task- or relationship-oriented leadership styles, but necessarily not both. The findings of high relationship-orientation and high task-orientation is very similar to previous findings of studies with working adult Afghans (Nguyen et al., 2014a; Mujtaba \& Sadat, 2010; Mujtaba \& Kaifi, 2010). In this research, male healthcare respondents showed relationship-oriented leadership contingent on their Afghan identity; in other words, the more they identified with the Afghan culture, the more 
relationship-oriented they were, and vice versa. If these male respondents saw themselves to be more American than Afghan based on their cross-cultural identity, then they were less relationship oriented.

This research demonstrated that male healthcare respondents who were strongly task-oriented were not task-oriented because they were Americanized or even Afghani in outlook, but more so because they were NOT relationship-oriented. Our research demonstrated that relationship orientation was strongly related to a man's Afghan identity. Afghanistan has been a tribal society for many centuries where familial connections and rivalries can be very strong as people tend to associate themselves with tribes or even certain cliques within ethnic groups (Mujtaba, 2013). Since Afghanistan has traditionally been very conservative, paternalistic and maledominated, where men worked outside of the house and often far from the local community while older women controlled household decisions, it is expected that men will practice relationship-oriented leadership as part of their Afghan acculturation and identity, but this is not necessarily the case with Afghan women. Due to centuries of socialization, customs and norms in Afghanistan, being associated with a specific tribe tends to carry certain image and respect with it. As such, relationship orientation and tribal connections do seem to be fairly strong in Afghanistan. Today, the Afghanistan culture is still hierarchical where age and rank are often revered due to the socialization and acculturation cycles of the patriotic community, especially by men as they are more likely to be followers and protectors of traditional norms.

It is not surprising that men associated with the Afghan culture are influenced to be more relationship-oriented. In this study, for male respondents, the relationshiporiented leadership was related to both the Afghan acculturation and more weakly to the American acculturation. In other words, the more acculturation and identification the male healthcare professional had with the American culture, the more relationship orientation he was expected to demonstrate). On the other hand, our study showed that the task-oriented leadership acculturation was in effect unrelated to acculturation. We did not find any statistically significant relationship between task-orientation and acculturation. Perhaps this is partially due to the strong association of relationship-orientation that is emphasized in the Afghan culture from a young age, where task-orientation usually comes second to family and community responsibilities. For example, when it comes to major holidays, death in the family, and illnesses impacting one's parents, an individual is expected to put family first and not worry about the job as professional tasks can always be completed by others or during another day. However, serving one's family, especially parents, cannot and should not be taken for granted.

For the women Afghan-American healthcare professionals, the findings were interesting and somewhat surprising. We found that female healthcare professionals had the largest association as the negative correlation between Afghan and American acculturation. Similar to the Afghan-American men, the women healthcare professionals identified with the Afghan culture or the American culture, but not necessarily with both cultures. Surprising though, the female healthcare professionals' task-orientation was strongly and directly related to the extent of their Afghan identity: the stronger their association with the Afghan identity, the more task-oriented they were, and vice versa. This is a statistically significant gender difference among 
the male and female Afghan-American healthcare professionals who are working in the nursing industry in the United States of America. Once again, perhaps the strong association with the Afghan identity and task-orientation of females come from the centuries of cultural socialization which are passed on from one generation to the next. Of course, the passage of norms and cultural practices do not get left behind when families migrate or move into new countries and diverse cultures.

Our research demonstrated that the American acculturation was unrelated to either form of leadership for Afghan-American healthcare professionals. However, for men the American acculturation was modestly related to their leadership style. Like the men, the women either identified with the American or the Afghan culture. One of the two gender differences was in leadership style. The male AfghanAmerican healthcare professionals had one specific leadership style or the other, but not necessarily both, which is indicated by the large negative correlation between their task- and relationship-orientations. In contrast, the Afghan-American female healthcare professionals showed a small correlation at best. This suggested that these Afghan-American women did not have a specific leadership style. One interpretation might be that, unlike the men, the women did not strongly adhere to either leadership style, which suggests that they shifted between styles as needed based on the situation and were perhaps more flexible leaders. Men were more strongly differentiated with respect to leadership orientation, but women showed no similar level of differentiation. One conclusion is that Afghan-American men tend to have their minds made up when it comes to the practice of effective leadership in a given situation. In other words, these Afghan-American men might prejudge certain situations without taking unique variables of the situation and current facts into consideration; as such, these men may see leadership as always appearing brave, strong, domineering, loud, and decisive regardless of the situational factors. On the other hand, Afghan-American women might assess the situation with an open mind and then practice the style of leadership that is needed, which can include the simple practice of empathy and listening without necessarily offering any guidance or direction.

Overall, as already mentioned, relationship-orientation correlated with all of the potential predictor variables. And, Afghan acculturation and annual income correlated significantly with relationship-oriented leadership and were entered as predictors.

\section{Limitations}

This study was limited in scope and time due to the difficulty of finding qualified individuals who met the criteria of being Afghan-American, socialized by both cultures, and being professional healthcare professionals in the nursing industry. The significant limitations of the current study include Afghan-American nurse's willingness to participate and lack of external verification that each participant was a nurse of Afghan descent. Limitations further include potential exposure to unique healthcare experiences that affected a personal leadership style or willingness to disclose personal leadership style honestly. In addition, this study recruited a sample of participants who provided self-reported data, which could not be verified. Future 
researchers should also include a qualitative element to this study when it is being replicated with healthcare professionals or other cross-cultural populations. While we do understand that this study is meaningful to human resource management practitioners and health professionals and policy-makers, especially during the Covid-19 pandemic, it is noted that future researcher can use more sophisticated, rigorous and diverse statistical methodologies to confirm these results.

\section{Recommendations}

Over the past four decades, since the occupation of the former Soviet Union's military in Afghanistan in 1979, millions of Afghans have become refugees all over the globe, especially in the United States. As such, Afghan-American professionals work in every industry in the United States of America. This study has empirically shown that Afghan-American healthcare professionals are highly relationship-oriented.

Compared to the females, Afghan-American men may need to become more open to hearing and understanding the needs of their followers and then leading based on whatever style of leadership is most appropriate. While all professionals can use leadership development, we recommend that Afghan-American men make effective use of situational leadership practices by assessing whether they need to use the telling, selling, participating, or delegating style of leadership with their followers and patients based on current facts surrounding the situation.

\section{Conclusion}

Socialization, especially cross-cultural acculturation, is an important influence on a person's values, work ethics, and leadership practices. In this study, we looked at the impact of Afghan and American society's acculturation on the leadership styles of healthcare professionals in the nursing field in the United States. This acculturation impact is ever more important to assess, as the nursing profession has diversified into many subspecialties within the medical industry, and nurses are increasingly providing more patient care. This study used a quantitative research process to see if gender, education, income, primary language, and level of acculturation predict task- and relationship-oriented leadership styles.

In this study, we wanted to know if there any correlations between acculturation, gender, education level, income, primary language, and task-oriented/relationshiporiented leadership style. Our result demonstrate that there are correlations between acculturation, gender, education level, and leadership styles. Furthermore, we wanted to know if acculturation, gender, education level, income, and primary language can predict task-oriented/relationship-oriented leadership. The answer to this question was yes.

Overall, the findings demonstrated that the cross-cultural male and female nurses often identify with either the Afghan culture or the American culture. Afghan male nurses tended to exhibit task or relationship-oriented leadership styles. We also 
found that high relationship orientation was strongly related to the male's Afghan identity. Afghan female nurses' task-orientation was strongly and directly related to the extent of their Afghan identity.

The results showed that Afghan male and female nurses tended to identify with the Afghan culture or the American culture, not both. Afghan male nurses' relationship-oriented leadership was related to both Afghan and (more weakly) American acculturation (the more acculturation, the more relationship orientation).

Public and private sector healthcare professionals should know that AfghanAmerican men significantly value their relationships with their bosses, colleagues and organization, and therefore are expected to be highly loyal. Similarly, executives, managers and policy-makers can feel confident that Afghan-American female professionals are excellent situational leaders; as such, in the healthcare industry, these female Afghan-Americans will take good care of their patients since they are highly task-oriented and will lead based on the needs of each situation. Given the existing complex challenges facing the healthcare industry in the United States, professional administrators and managers should provide more leadership opportunities for the task-oriented female Afghan-American situational leaders who are very taskoriented as they are likely to take good care of each patient while working strategically working toward a brighter future for each individual.

\section{Declarations}

Ethical Approval Proper IRB procedures were followed in this study.

Informed Consent Not applicable for this case study.

Conflict of Interest None

\section{References}

Aseel, M. Q. (2003). Torn between two cultures. Capital Books Inc.

Azizi, M. (2008). Leaders of higher education in Afghanistan: Leadership beliefs and challenges for the 21st century (Order No. 3336791). ProQuest Dissertations \& Theses Global. (304825477).

Begum, R., \& Mujtaba, B. G. (2016). Task and relationship orientation of Pakistani managers and working professionals: The interaction effect of demographics in a collective culture. Public Organization Review, 16(2), 199-215.

Blais, N. (2019). I am because we are: Awakening revolutionary patient-centered care. Journal of Emergency Nursing, 45(2), 211-213.

Blake, R. R., \& Mouton, J. S. (1966). Managerial facades. Advanced Management Journal, 31(3), 30-37.

Cann, A., \& Siegfried W. D. (1990). Gender stereotypes and dimensions of effective leader behavior. Sex Roles, 23, 413-419.

Caplin-Davies, P. (2003). Management and leadership - A dual role in nursing education. Nurse Education Today, 23(1), 3-10.

Colquitt, J., Lepine, J., \& Wesson, M. (2011). Organizational behavior: Improving performance and commitment in the workplace. McGraw-Hill/Irwin.

Cowsill, R., \& Grint, K. (2008). Leadership, task and relationship: Orpheus, Prometheus and Janus. Human Resource Management Journal, 18(2), 188-195. https://doi.org/10.1111/j.1748-8583.2007. 00065.x. 
Cuéllar, I., Arnold, B., \& Maldonado, R. (1995). Acculturation rating scale for Mexican Americans-II: A revision of the original ARSMA scale. Hispanic Journal of Behavioral Science, 17(3), 275-304.

Curran, C. L., \& Sigma Theta Tau International. (2016). Nurse on Board: Planning Your Path to the Boardroom. Sigma Theta Tau International.

Dusek, G., Yurova, Y., \& Ruppel, C. (2015). Using social media and targeted snowball sampling to survey a hard-to-reach population: A case study. International Journal of Doctoral Studies, 10, 279-299.

Fernandez, A. A., \& Shaw, G. P. (2020). Academic leadership in a time of crisis: The coronavirus and COVID-19. Journal of Leadership Studies, 14(1), 1-7. https://doi.org/10.1002/j1s.21684.

Fitzpatrick, J. J., Ea, E. E., \& Bai, L. S. (2017). 301 Careers in Nursing. Springer Publishing Company.

Fleishman, E. A. (1953). The description of supervisory behavior. Journal of Applied Psychology, 37, $1-6$.

Frögéli, E., Rudman, A., and Gustavsson, P. (2019). The relationship between task mastery, role clarity, social acceptance, and stress: an intensive longitudinal study with a sample of newly registered nurses. International Journal of Nursing Studies, 91, 60-69. https://doi.org/10.1016/j.ijnurstu.2018. 10.007 .

George, L. (1993). Children of immigrants often torn between two cultures: Assimilation as parents continue to bring their families' hopes and expectations to the United States, a complex tension can develop for young new Americans. Los Angeles Times. http://articles.latimes.com/1993-11-28/ local/me-61948_1_united-states/2.

Grossman, S., \& Valiga, T. (2012). The new leadership challenge - creating the future of nursing. (4th ed.). FA Davis Company.

Hirschman, C. (2013). The contributions of immigrants to American culture. Daedalus, 142(3), 1-19.

Hunt, D. D. (2017). Fast Facts About the Nursing Profession: Historical Perspectives in a Nutshell. Springer Publishing Company.

Iron Cloud, R. (2019). Leadership values and acculturation among the Oglala Lakota leadership (Order No. 22621056). Available from ProQuest One Academic. (2314265466).

Judge, T. A., Piccolo, R. F., \& Ilies, R. (2004). The forgotten ones? The validity of consideration and initiating structure in leadership research. Journal of Applied Psychology, 89(1), 36-51.

Katz, D., Maccoby, N., \& Morse, N. (1950). Productivity, supervision, and morale in an office situation. Institute for Social Research, University of Michigan.

Kavanaugh, J. K. (1986). The content of implicit leadership theories: An investigation of achievement orientation, task orientation, and relationships orientation under varied task difficulty and achievement conditions (Order No. 8629179). ProQuest Dissertations \& Theses Global.

Korman, K., \& Mujtaba, B. G. (2020). Corporate responses to COVID-19 layoffs in North America and the role of human resources departments. Reports on Global Health Research, 3(2), 1-17. https:// doi.org/10.29011/2690-9480.100122.

Lockwood, C. (2020). Nurses as substitutes for doctors in primary care. International Journal of Nursing Studies, 106, 103362.

Ludwick, R., \& Silva, M. (2000). Ethics: Nursing around the world: Cultural values and ethical conflicts. Online Journal of Issues in Nursing, 5(3), 1-10.

Miller, M. J., \& Kerlow-Myers, A. E. (2009). A content analysis of acculturation research in the career development literature. Journal of Career Development, 35(4), 352-384.

Mujtaba, B. (2010). An examination of Bahamian respondents' task and relationship orientations: Do males have a significantly different score than females? Journal of Diversity Management, 5(3), $35-41$.

Mujtaba, B. G. (2013). Ethnic diversity, distrust and corruption in Afghanistan: Reflections on the creation of an inclusive culture. Equality, Diversity and Inclusion: An International Journal, 32(3), $245-261$.

Mujtaba, B. G. (2019). Leadership and management philosophy of "Guzaara" or cooperating to "Get Along" in South Asia's Afghanistan. Business Ethics and Leadership, 3(1), 44-57.

Mujtaba, B. G., \& Alsua, C. J. (2011). Task and relationship orientation of Americans: A study ofgender, age, and work experience. Journal of Behavioral Studies in Business, 3(1), 27-36.

Mujtaba, B. G., \& Kaifi, B. A. (2010). An inquiry into eastern leadership orientation of working adults in Afghanistan. Journal of Leadership Studies, 4(1), 36-46.

Mujtaba, B. G., Khanfar, N. M., \& Khanfar, S. M. (2010). Leadership tendencies of government employees in Oman: A study of task and relationship based on age and gender. Public Organization Review, 10(2), 173-190. 
Mujtaba, B. G., \& Sadat, S. K. (2010). Leadership knowledge of local and expatriate Afghans: Are they leaning more toward tasks or relationships? Journal of Business Studies Quarterly, 1(3), 1-12.

Nguyen, L. D., Mujtaba, B. G., \& Ruijs, A. (2014a). Stress, task, and relationship orientations of Dutch: Do age, gender, education, and government work experience make a difference? Public Organization Review, 14(3), 305-324.

Nguyen, L. D., Mujtaba, B. G., Tran, Q. H. M., \& Tran, C. N. (2014b). Do age and management experience make a difference in leadership orientations? An empirical study of Omani and Vietnamese working adults. Academy of Business Disciplines Journal, 6(1), 1-16.

Nguyen, L. D., Mujtaba, B. G., Tran, Q. H. M, \& Tran, C. N. (2014c). Do age and management experience make a difference in leadership orientations? An empirical study of Omani and Vietnamese working adults. Academy of Business Disciplines Journal, 6(1), 1-16.

Northouse, P. (2004). Leadership: Theory and practice. (3rd ed.). SAGE Publications.

Paris, T. D. J. (2003). Acculturation, assimilation, leadership styles and its consequences on job satisfaction (Order No. 3088536). ProQuest Dissertations \& Theses Global. (305216527).

Pielstick, C. D. (2000). Formal vs. informal leading: A comparative analysis. Journal of Leadership and Organizational Studies, 7(3), 99-114.

Politis, J. D., Politis, D. J., \& Politis, N. J. (2018). Initiating structure and consideration leadership creativity and innovation relationships: The Cypriot and the United Arab Emirates experience. Proceedings of the European Conference on Management, Leadership \& Governance, 213-220.

Rahmani, A. I. (2016). Political leadership in Afghanistan: Identifying and assessing determining factors (Order No. 10587685). ProQuest Dissertations \& Theses Global. (1885103267).

Rigoloski, E. (2013). Management and leadership in nursing and health care: An experiential approach. Springer Publishing Co.

Rogers, D. M. (2017). Emergence of informal clinical leadership among bedside nurses in the acute care clinical setting: A mixed methods study (Order No. 10638387). ProQuest Dissertations \& Theses Global.

Schermerhorn, J. R., Hunt, J. G., \& Osborn, R. (2008). Organizational behavior. (10th ed.). Wiley.

Scully, J. N. (2015). Leadership in nursing: The importance of recognizing inherent values and attributes to secure a positive future for the profession. Collegian, 22(4), 439-444.

Senathip, T., Mujtaba, B. G., \& Cavico, F. J. (2017). Policy-making considerations for ethical and sustainable economic development. Economy, 4(1), 7-14.

Sherwood, A., \& DePaolo, C. (2005). Task and relationship-oriented trust in leaders. Journal of Leadership and Organization Studies, 12(2), 65-81.

Tabachnick, B. G., \& Fidell, L. S. (2019). Using multivariate statistics. (7th ed.). Pearson.

Tajaddini, R., \& Mujtaba, B. G. (2010). Stress and leadership tendencies of respondents from Iran: Exploring similarities and differences based on age and gender. Public Organization Review, 11, 219-236.

Tjosvold, D., \& Leung, K. (2016). Cross-cultural management: Foundations and future. Routledge.

Trevino, D. (2010). Acculturation and leadership styles of elected Latino leaders (Order No. 3411402). ProQuest Dissertations \& Theses Global. (527854489).

Zareen, M., Razzaq, K. and Mujtaba, B. G. (2015). Impact of Transactional, Transformational and Laissez-Faire Leadership Styles on Motivation: A Quantitative Study of Banking Employees in Pakistan. Public Organization Review, 15(4), 431-549. https://doi.org/10.1007/s11115-014-0287-6. Link: http://link.springer.com/article/10.1007/s11115-014-0287-6.

Zoppi, I. M. (2004). The relationship of self-perceived leadership style and acculturation of Latinas in the United States Army (Order No. 3152509). ProQuest Dissertations \& Theses Global. (305176366).

Publisher's Note Springer Nature remains neutral with regard to jurisdictional claims in published maps and institutional affiliations.

Belal A. Kaifi is a professor of Business Administration at Trident University. He completed his postdoctoral studies in Business Administration at the University of Florida and completed a doctoral degree (Ed.D.) in Organization and Leadership at the University of San Francisco and a second doctoral degree (Ph.D.) in Health Care Administration and Policy at American InterContinental University. Belal's broad research interests include topics related to cross-cultural management, diversity management, and strategic leadership. 
Bahaudin G. Mujtaba is Professor of Management and Human Resources at Nova Southeastern University in Ft. Lauderdale, Florida. Bahaudin is the author and co-author of several professional and academic books dealing with leadership, cross-cultural diversity, ethics, and management, as well as numerous academic journal articles. During the past thirty years he has had the pleasure of working with human resource professionals in the United States, Afghanistan, Pakistan, Canada, Brazil, Bahamas, St. Lucia, Grenada, Malaysia, Japan, Vietnam, China, India, Thailand, and Jamaica. Bahaudin was born Khoshie of Logar Province, and raised Kabul of Afghanistan. He migrated to the United States of America when he was a teenager. Bahaudin can be reached at: mujtaba@nova.edu

Mustafa G. Mujtaba is an Assistant Professor of Immunology and Microbiology with the Biological Sciences Department at Florida Gulf Coast University in Fort Myers, Florida. He obtained his Bachelors of Science and Doctor of Philosophy degrees from the University of Florida, Gainesville, Florida, and conducted his postdoctoral research fellowship at Brigham and Women's Hospital, Harvard Medical School, in Boston, Massachusetts. During the past fifteen years he thought courses in chemistry, immunology, and microbiology for the College of Arts and Sciences and for the Nurse Anesthesia program in the College of Health Professions, at FGCU. His current research involves working with student in the development of antimicrobial drugs, elucidating the mechanism and therapy of immune disorders, and development of long-acting local anesthetic activity. 